\title{
Fraction of photosynthetically active radiation absorbed by Amazon tropical forest: A comparison of field measurements, modeling, and remote sensing
}

\author{
Mônica C. A. Senna and Marcos H. Costa \\ Department of Agricultural and Environmental Engineering, Federal University of Viçosa (UFV), Viçosa, Minas Gerais, \\ Brazil
}

Yosio E. Shimabukuro

Department of Remote Sensing, National Institute for Space Research (INPE), São José dos Campos, São Paulo, Brazil

Received 10 December 2004; revised 29 April 2005; accepted 13 June 2005; published 15 September 2005.

[1] The fraction of absorbed photosynthetically active radiation (FAPAR) is a vegetation biophysical variable that characterizes energy, mass, and momentum exchanges and is used extensively in models that represent the transfer of energy, carbon, water, and the biogeochemistry of terrestrial ecosystems. This paper compares three estimates of FAPAR by an Amazonian tropical rain forest. In the Tapajós National Forest, near Santarém, state of Pará, Brazil, FAPAR is estimated based on field measurements, modeling (using IBIS which simulates the fluxes in the soil-vegetation-atmosphere system considering two vegetation layers) and remotely sensed Moderate Resolution Imaging Spectroradiometer (MODIS) monthly FAPAR product, which has not been validated for a tropical rain forest yet. FAPAR based on field observations is calculated from incoming and reflected PAR measurements taken above the canopy, and downward PAR at a $15 \mathrm{~m}$ height, corrected to be representative of the entire canopy, obtaining an annual mean value of 0.91. FAPAR simulated by the Integrated Biosphere Simulator (IBIS) is 0.76, while the annual average FAPAR estimated by MODIS is 0.85 . If we consider that MODIS estimates include only PAR absorbed by leaves, the remote sensing estimates are very close to field measurements corrected to include only the absorption by leaves $(0.87)$; hence we conclude that the MODIS FAPAR product for the tropical rain forest is reliable to be used in future studies. However, model estimates of FAPAR for the tropical forest are low, and adjustments on the algorithm used to calculate the absorbed radiation by the canopy are necessary.

Citation: Senna, M. C. A., M. H. Costa, and Y. E. Shimabukuro (2005), Fraction of photosynthetically active radiation absorbed by Amazon tropical forest: A comparison of field measurements, modeling, and remote sensing, J. Geophys. Res., 110, G01008, doi:10.1029/2004JG000005.

\section{Introduction}

[2] Accurate monitoring of changes in the terrestrial biosphere has become increasingly important as the human impacts on biological systems and atmospheric chemistry grow. The detection of interannual variability and long-term trends of ecosystem structure permits early indication of fundamental changes in the biosphere, which would otherwise go undetected until major biome conversion begins [Running et al., 1999].

[3] Tropical rain forests are among the most important biomes of the planet in terms of fluxes of energy, water and carbon. According to Williams et al. [1998], although tropical rain forests extend over only about $8 \%$ of the global land surface $\left(\approx 12 \cdot 10^{6} \mathrm{~km}^{2}\right)$, they contain about

Copyright 2005 by the American Geophysical Union. 0148-0227/05/2004JG000005\$09.00
$40 \%$ of the biomass (240 Pg C) and account for about $50 \%$ of the annual net primary production of the biosphere $\left(\approx 30 \mathrm{Pg} \mathrm{C} \cdot \mathrm{a}^{-1}\right)$.

[4] The productivity of a vegetated surface is related, among other factors, to the photosynthetically active radiation (PAR) absorbed by the vegetation. The fraction of absorbed PAR (FAPAR) is defined by the ratio APAR/ $\mathrm{PAR}_{\text {in }}$, where $\mathrm{PAR}_{\text {in }}$ is the incident PAR on the top of the canopy and APAR is the PAR absorbed by the photosynthesizing tissue of the canopy. FAPAR may be used to characterize energy, mass and momentum exchanges between the canopy and the atmosphere and is extensively used in models that represent the transfer of energy, carbon, water, and biogeochemistry of terrestrial ecosystems. The most significant variables to determine FAPAR are land cover, leaf area, solar angle, proportion of diffuse radiation and soil reflectance [Myneni and Williams, 1994; Mariscal et al., 2000; Nouvellon et al., 2000]. 
[5] A detailed estimation of FAPAR requires long term monitoring with high temporal and spatial resolution, which demands a triple methodology, combining field measurements, remote sensing and modeling. While the high temporal resolution monitoring may be obtained by field measurements, remote sensing is used to quantify the spatial heterogeneity of FAPAR and, since the temporal and spatial measurements cannot provide a complete view of the ecosystem, modeling is required to isolate unmeasured ecosystem processes and to provide predictive capacity [Running et al., 1999].

[6] One of the recent improvements in remote sensing is MODIS (Moderate Resolution Imaging Spectroradiometer), the main high temporal frequency global mapping sensor onboard the Terra and Aqua satellites. MODIS acquires data in 36 spectral bands between $0.4-14.4 \mu \mathrm{m}$ with spatial resolution of $250 \mathrm{~m}$ ( 2 bands), $500 \mathrm{~m}$ (5 bands) and $1 \mathrm{~km}$ (29 bands) [Running et al., 1994, 1999; Cohen and Justice, 1999], and is ideal for monitoring large-scale changes in the biosphere that will yield new insights into the workings of the global carbon cycle. MODIS products include surface reflectance and temperature, and from these, spectral vegetation index, leaf area index, land cover, net primary productivity and FAPAR. These and other products play an important role in measuring and monitoring surface variables, and in the development and validation of global ecosystem models [Cohen and Justice, 1999].

[7] By modeling the radiative transfer through a canopy using a process-based model, it is possible to understand the absorption, transmission and reflection of radiation by leaves, branches and soil surface, at the same time the model's ability to reproduce the measured values can be assessed. A model of the Earth's biosphere, the Integrated Biosphere Simulator (IBIS) [Foley et al., 1996], was developed as a first step toward gaining an improved understanding of global biospheric processes and studying their potential response to human activity. IBIS is one of the new generation of global biosphere models, named Dynamic Global Vegetation Models, that considers changes in vegetation composition and structure in response to environmental change. This model represents a wide range of processes, including interactions between land and atmosphere, carbon and nutrient cycling and vegetation dynamics, and is also coupled to climate models, allowing studies of the long-term interactions between biosphere and atmosphere.

[8] Here in this paper, we compare FAPAR estimates by IBIS and MODIS for a tropical rain forest with field measurements collected at a micrometeorological site in Amazonia. Section 2 describes the site where field measurements were taken, and section 3 describes the three methodologies used (field measurements, modeling and remote sensing). Section 4 discusses the results obtained by each methodology, while section 5 presents an overall discussion of the results, comparing the three methodologies and indicating strengths and limitations of each one. The final section presents a summary and conclusions of the work.

\section{Site Description}

[9] Data used in this work were collected at the IBAMA Tapajós National Forest (Flona Tapajós), a primary tropical

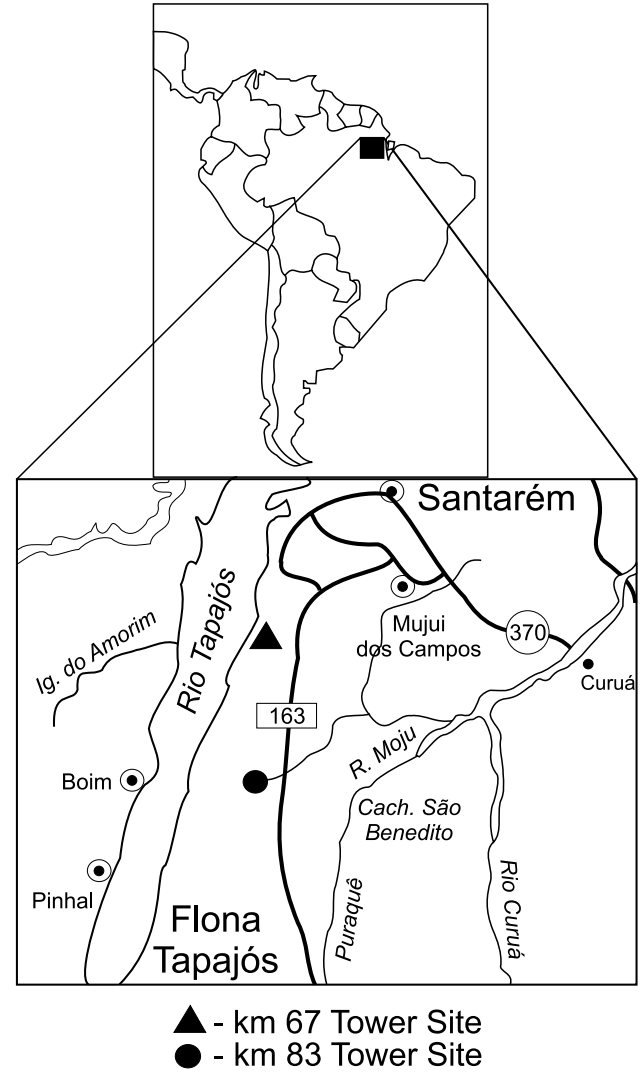

Figure 1. Location of the experimental area.

forest area located in Santarém, state of Pará, Brazil (Figure 1). The canopy is characterized by large emergent trees up to $55 \mathrm{~m}$ tall, and a closed canopy at $\approx 40 \mathrm{~m}$; there are few indications of recent anthropogenic disturbance other than hunting trails. Soils are nutrient-poor clay oxisols with low organic content and low cation exchange capacity [Saleska et al., 2003]. The mean leaf area index (LAI) measured on the field is 5.6 (unpublished data).

\section{Methods}

\subsection{Field Measurements}

[10] The PAR components in the Flona Tapajós are studied by two time series, one collected at the tower close to $\mathrm{km} 67$ on the Cuiabá-Santarém Highway, and the other at the tower close to $\mathrm{km} \mathrm{83}$. Both towers have two PAR sensors, but they are installed differently. At $\mathrm{km} 67$ $\left(2.855^{\circ} \mathrm{S} ; 55.036^{\circ} \mathrm{W}\right)$, the sensors measure the downward PAR, but one is installed above the canopy $(58 \mathrm{~m}$ high, $\left.\mathrm{PAR}_{\text {in }}\right)$ while the other is $15 \mathrm{~m}$ above the ground $\left(\mathrm{PAR}_{15 \mathrm{~m}}\right)$, above the understory vegetation. Later, these data are corrected to become representative of the entire canopy. At $\mathrm{km} 83\left(3.018^{\circ} \mathrm{S} ; 54.971^{\circ} \mathrm{W}\right)$, both are installed on the top of the canopy, one measuring the incident PAR $\left(\mathrm{PAR}_{\text {in }}\right)$ and the other measuring the reflected PAR $\left(\mathrm{PAR}_{\text {out }}\right)$. Therefore data from $\mathrm{km} 67$ are used to study radiation inside the canopy, while those from $\mathrm{km} 83$ are used to quantify the radiation reflected by the forest. We use $\mathrm{km} 67$ data collected from April 2001 to October 2002, and km 83 data collected from June 2000 to June 2001, prior to the selective logging at the $\mathrm{km} 83$ site in September 2001. 

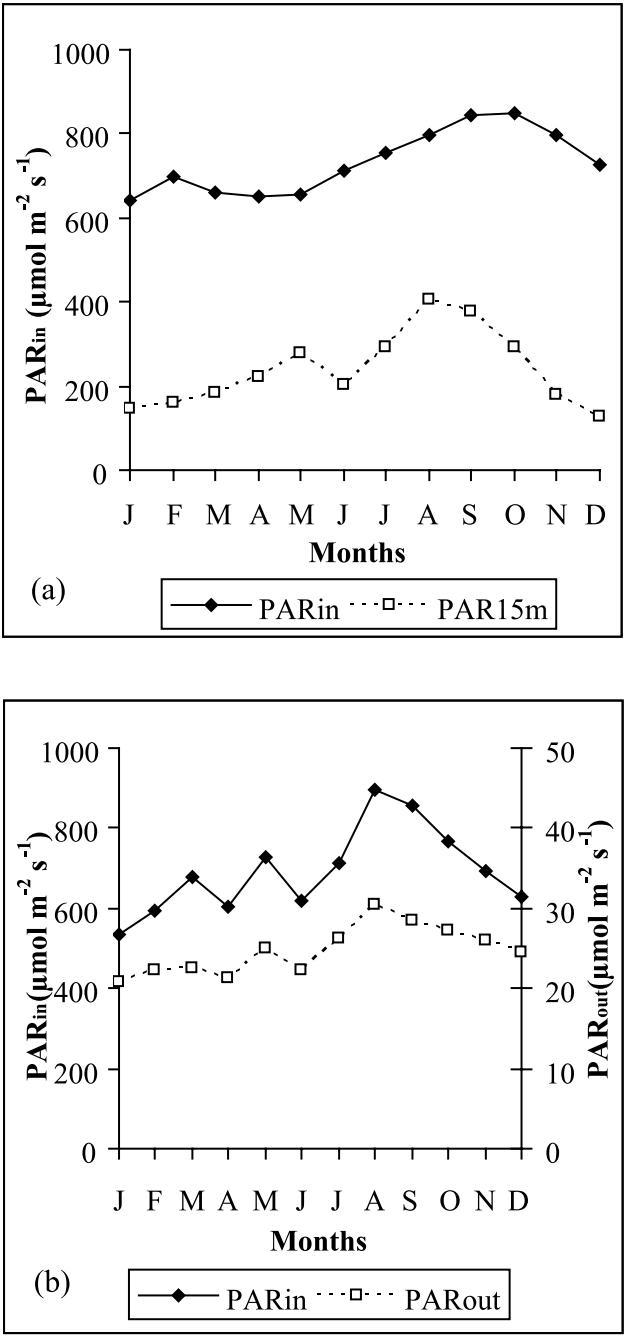

Figure 2. Monthly mean of (a) incident PAR observed above the canopy and at $15 \mathrm{~m}$ from the ground at $\mathrm{km} 67$ and (b) incident and reflected PAR observed above the canopy at $\mathrm{km} 83$.

[11] FAPAR between top of canopy and $15 \mathrm{~m}$ $\left(\right.$ FAPAR $_{\text {top-15m }}$ ) is calculated assuming that $\mathrm{r}$ (PAR reflectance, $r=$ PAR $\left._{\text {out }} / \mathrm{PAR}_{\text {in }}\right)$ and $t_{\text {top- } 15 \mathrm{~m}}(\mathrm{PAR}$ transmittance between top and $\left.15 \mathrm{~m}, \mathrm{t}_{\text {top-15m }}=\mathrm{PAR}_{15 \mathrm{~m}} / \mathrm{PAR}_{\text {in }}\right)$ do not vary between the sites ( $\mathrm{r}$ is obtained from $\mathrm{km} 83$ data and $\mathrm{t}$ from $\mathrm{km} 67 \mathrm{data}$ ), and that the PAR reflected by the soil surface is negligible [Gower et al., 1999],

$$
\begin{aligned}
\text { FAPAR }_{\text {top-15m }}= & {\left[\left(\mathrm{PAR}_{\text {in }}-\mathrm{PAR}_{\text {out }}\right)\right.} \\
& \left.-\left(\mathrm{PAR}_{15 \mathrm{~m}}-\mathrm{PAR}_{\text {out_soil }}\right)\right] / \mathrm{PAR}_{\text {in }},
\end{aligned}
$$

which can be re-written as

$$
\text { FAPAR }_{\text {top- } 15 \mathrm{~m}}=1-\mathrm{r}-\mathrm{t}_{\text {top- } 15 \mathrm{~m}} .
$$

\subsection{Modeling}

[12] The IBIS land surface model simulates the exchanges of energy, water, $\mathrm{CO}_{2}$ and momentum in the soil-vegetation-atmosphere system. The model represents two vegetation layers (trees and grasses) and eight soil layers. The model uses a 60-min integration interval to capture the diurnal cycle of the biophysical and physiological processes. The version 2.6.4 IBIS is calibrated against 2000 to 2001 data from the $\mathrm{km} 83$ site. The calibration consisted simply of the update of the coefficient $\mathrm{f}_{\mathrm{vis}}$ (below) using the value obtained by a least squares fit between the incoming PAR and the incoming shortwave radiation. Next, the model was run forced by $\mathrm{km} 67$ data, with a one-hour integration interval for the period 11 April 2001 to 2 October 2002.

[13] IBIS calculates the solar radiation for each vegetation level with separate computations for direct and diffuse radiation in two wavelength bands (visible and near infrared). In ecosystem models coupled to climate models, such as IBIS, the incident PAR is usually calculated from the incoming solar radiation, according to equations like equation (3),

$$
\begin{aligned}
\mathrm{PAR}_{\text {in }} & =\mathrm{PAR}_{\text {udir }}+\mathrm{PAR}_{\text {udif }} \\
& =\left[\mathrm{Q}_{\text {top }} \cdot 4.59 \cdot \mathrm{f}_{\text {vis }} \cdot\left(1-\mathrm{f}_{\text {dif }}\right)\right]+\left[\mathrm{Q}_{\text {top }} \cdot 4.59 \cdot \mathrm{f}_{\text {vis }} \cdot \mathrm{f}_{\text {dif }}\right],
\end{aligned}
$$

where $\mathrm{PAR}_{\text {udir }}$ is the incident direct PAR in the upper canopy, PAR udif $_{\text {is }}$ the incident diffuse PAR in the upper canopy, $\mathrm{Q}_{\text {top }}$ is the incident solar radiation at the canopy top (measured at the tower), $f_{v i s}$ is the energy fraction of the visible band $\left(0.427\right.$, calibrated coefficient) and the $f_{\text {dif }}$ is the fraction of diffuse solar radiation, calculated according to Nikolov and Zeller [1992] and Friend [1998]. In this study, although we force IBIS with field-measured data, we choose to force the model with incoming solar radiation and convert it to incoming PAR, rather than force it with incoming PAR. This is done to keep compatibility with other applications of the model, notably when the model is forced by atmospheric models or by climate data. Total APAR is calculated as the sum of the upper and lower canopy APAR,

$$
\begin{aligned}
\operatorname{APAR}_{\mathrm{t}}= & \left(\mathrm{PAR}_{\text {udir }} \cdot \mathrm{a}_{\text {udir }}+\mathrm{PAR}_{\text {udif }} \cdot \mathrm{a}_{\text {udif }}\right) \\
& +\left(\mathrm{PAR}_{\text {Idir }} \cdot \mathrm{a}_{\text {ldir }}+\mathrm{PAR}_{\text {ldif }} \cdot \mathrm{a}_{\text {ldif }}\right),
\end{aligned}
$$

where $a_{u d i r}$ is the fraction of direct PAR absorbed by the upper canopy, $a_{\text {udif }}$ is the fraction of the diffuse PAR absorbed by the upper canopy, PAR $_{\text {Idir }}$ is the direct PAR incident on the lower canopy, $\mathrm{a}_{1 \mathrm{ldi}}$ is the fraction of PAR absorbed by the lower canopy, and PAR ${ }_{1 \text { dif }}$ and $a_{\text {ldif }}$ have the same significance, for diffuse PAR. The radiation transmittance through the canopy and the absorptance coefficients are dynamically calculated by IBIS as a function of the zenith angle, leaf area index, leaf orientation, and transmission and scattering coefficients, according to the methodology proposed by Sellers [1985]. The absorptance coefficients include the absorption by leaves, branches and stems. FAPAR is calculated by the ratio $\mathrm{APAR}_{\mathrm{t}} / \mathrm{PAR}_{\text {in }}$.

\subsection{Remote Sensing}

[14] The FAPAR products from MODIS are produced with a spatial resolution of $1 \mathrm{~km}$, and are provided as a daily product (MOD15A1), as a product from the maximum 

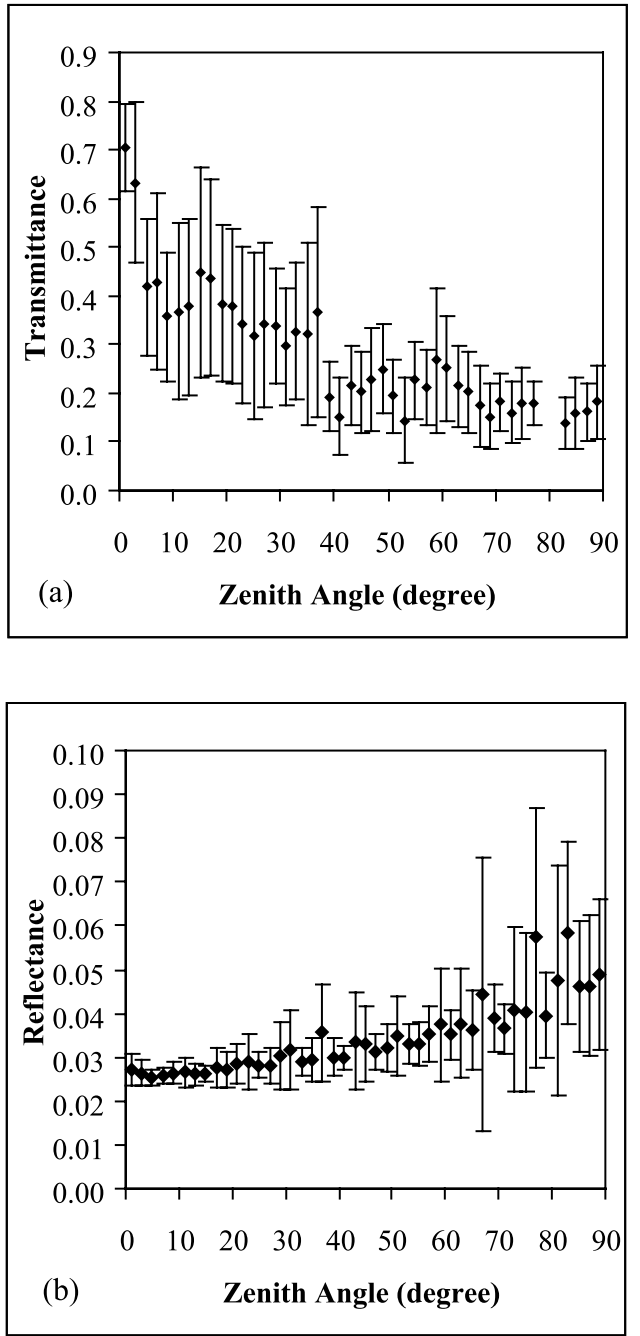

Figure 3. Monthly mean of (a) transmittance between the top of the canopy and $15 \mathrm{~m}$ at $\mathrm{km} 67$ and (b) reflectance at $\mathrm{km} \mathrm{83}$; as a function of the solar zenith angle. The bars represent the standard deviation.

value on a period of 8 days (MOD15A2), and as a monthly average product (MOD15_BU). The MODIS FAPAR algorithm is based on three-dimensional radiative transfer theory and developed by inversion using a look-up table approach [Privette et al., 2002; Myneni et al., 2002]. It has interfaces with the MODIS surface reflectance (MOD09) and land cover (MOD12) products. When this method fails to find a solution, a backup method based on the relationship between the normalized difference vegetation index (NDVI) and FAPAR is used [Myneni et al., 2002; Knyazikhin et al., 1999].

[15] The product used in this study is MOD15_BUcollection 4, that is produced and distributed by the Boston University and available at the address ftp://crsa.bu.edu/ pub/rmyneni/myneniproducts/MODIS. We used data from October 2001 to September 2002. The study area contains twenty-five $1 \mathrm{~km}^{2}$ cells and is situated between $2.85^{\circ} \mathrm{S}$ and $2.88^{\circ} \mathrm{S}$ and between $55.05^{\circ} \mathrm{W}$ and $55.01^{\circ} \mathrm{W}$, which includes the $\mathrm{km} 67$ tower.

[16] For each cell, we analyze the FAPAR value and the quality assessment (QA), which informs the type of algo- rithm used or the inexistence of data. The monthly FAPAR mean is obtained by the arithmetic mean of the 25 grid points, whenever data existed. From the QA value for each cell, we also calculate a quality index for each cell. This quality index assumes values from 4.0 to 2.5 if the primary algorithm was used, from 2.0 to 0.5 if the secondary algorithm was used, and zero if no data is available. The total quality index (QI) is the sum of the individual quality indexes for the 25 cells, and varies from zero to 100 . The greater the QI, the more reliable is the quality of the estimated FAPAR.

\section{Results}

\subsection{Field Measurements}

[17] Figure 2a presents the monthly variation in $\mathrm{PAR}_{\text {in }}$ and PAR $_{15 \mathrm{~m}}$ at the $\mathrm{km} 67$ site. The monthly PAR in values vary from 640 to $850 \mu \mathrm{mol} \mathrm{m} \mathrm{s}^{-2}$, with mean value of $732 \mu \mathrm{mol} \mathrm{m}{ }^{-2} \mathrm{~s}^{-1}$, while the monthly PAR $_{15 \mathrm{~m}}$ values vary between 129 and $404 \mu \mathrm{mol} \mathrm{m} \mathrm{m}^{-2} \mathrm{~s}^{-1}$ with a mean value of $239 \mu \mathrm{mol} \mathrm{m}{ }^{-2} \mathrm{~s}^{-1}$. Figure $2 \mathrm{~b}$ shows the monthly variation in $\mathrm{PAR}_{\text {in }}$ and $\mathrm{PAR}_{\text {out }}$ at the km 83 site. The minimum, mean and maximum PAR $_{\text {in }}$ values are 536, 693 and $894 \mu \mathrm{mol}$ $\mathrm{m}^{-2} \mathrm{~s}^{-1}$, respectively, and for PAR ${ }_{\text {out }}$ they are 21,25 and $30 \mu \mathrm{mol} \mathrm{m} \mathrm{s}^{-2}$. At both sites, the maximum values occur during the dry season and the minimum during the rainy season, when cloudiness is greater.

[18] The relationship between $t_{\text {top- } 15 \mathrm{~m}}$ and $\mathrm{r}$ with the solar zenith angle is illustrated in Figure 3. The lower values of $\mathrm{t}_{\text {top- } 15 \mathrm{~m}}$ occur at the higher zenith angles, when the path taken by the radiation within the canopy is longer, increasing the chance of absorption by leaves and branches. Figure $3 \mathrm{~b}$ shows the relationship of $\mathrm{r}$ with the solar zenith angle, showing that the reflectance increases with the zenith angle $(0.03$ to 0.05$)$ but are relatively low compared to changes in transmittance ( 0.2 to 0.7 ).

[19] We use the relationships obtained by Anhuf and Rollenbeck [2001] to correct the $\mathrm{km} 67$ transmittance values to a transmittance value representative of the entire canopy $\left(\mathrm{t}_{\text {top- } 0 \mathrm{~m}}\right)$. They studied the PAR transmittance behavior in a tropical forest in Venezuela (assumed similar to the structure of our study site), using PAR measurements every $10 \mathrm{~min}$ at five heights $(0,5,12,21$ and $42 \mathrm{~m})$. Between 5 and $21 \mathrm{~m}$, data were collected by a sensor coupled to an electric

Table 1. Monthly Means of $t_{\text {top- } 15 \mathrm{~m}}$ ( \pm the Standard Deviation)

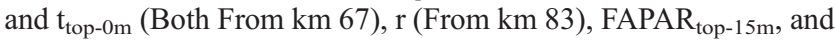
FAPAR $_{\text {top- } 0 \mathrm{~m}}$

\begin{tabular}{lccccc}
\hline & $\mathrm{t}_{\text {top-15m }}$ & $\mathrm{t}_{\text {top-0m }}$ & $\mathrm{r}$ & FAPAR $_{\text {top-15m }}$ & FAPAR $_{\text {top-0m }}$ \\
\hline January & $0.215 \pm 0.053$ & 0.040 & 0.031 & 0.754 & 0.929 \\
February & $0.221 \pm 0.080$ & 0.041 & 0.031 & 0.749 & 0.928 \\
March & $0.308 \pm 0.102$ & 0.058 & 0.027 & 0.665 & 0.915 \\
April & $0.330 \pm 0.136$ & 0.062 & 0.028 & 0.642 & 0.910 \\
May & $0.332 \pm 0.141$ & 0.062 & 0.029 & 0.639 & 0.909 \\
June & $0.303 \pm 0.155$ & 0.057 & 0.028 & 0.669 & 0.915 \\
July & $0.340 \pm 0.206$ & 0.064 & 0.031 & 0.629 & 0.905 \\
August & $0.452 \pm 0.238$ & 0.085 & 0.029 & 0.519 & 0.886 \\
September & $0.437 \pm 0.223$ & 0.082 & 0.028 & 0.535 & 0.890 \\
October & $0.317 \pm 0.146$ & 0.059 & 0.030 & 0.652 & 0.911 \\
November & $0.206 \pm 0.058$ & 0.039 & 0.032 & 0.762 & 0.929 \\
December & $0.168 \pm 0.031$ & 0.032 & 0.033 & 0.799 & 0.935 \\
Annual & 0.308 & 0.057 & 0.030 & 0.668 & 0.914 \\
$\quad$ mean & & & & & \\
\hline
\end{tabular}




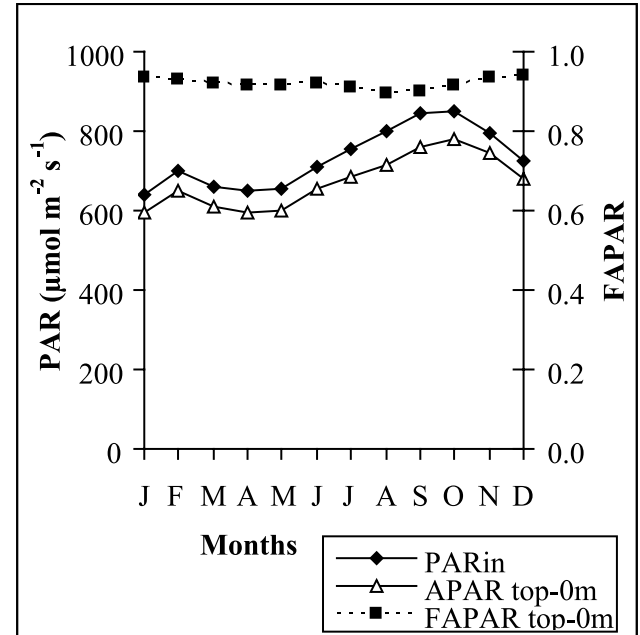

Figure 4. Monthly mean of $\mathrm{PAR}_{\text {in }}, \mathrm{APAR}_{\text {top- } 0 \mathrm{~m} \text {, and }}$ FAPAR $_{\text {top- } 0 \mathrm{~m}}$ of the observed data at $\mathrm{km} 67$.

system that went up or down at constant speed. According to their results, the ratio between the transmittance of the entire canopy $(4.5 \%)$ and the transmittance above $15 \mathrm{~m}$ $(24 \%)$ is 0.1875 . These data agree with the study by Januário et al. [1992], who compared the total solar radiation inside and outside the Tucuruí Forest, Pará (using sensors randomly installed on the forest ground and a sensor located in an open area) and reported that the ground radiation was $4.7 \%$ of the incident radiation.

[20] Thus the $t_{\text {top- } 15 \mathrm{~m}}$ values are multiplied by the ratio 0.1875 to obtain the $t_{\text {top- } 0 \mathrm{~m}}$ values. Table 1 shows the mean monthly values of $r, t_{\text {top- } 15 \mathrm{~m}}, \mathrm{t}_{\text {top- } 0 \mathrm{~m}}$, FAPAR $_{\text {top- } 15 \mathrm{~m}}$ and

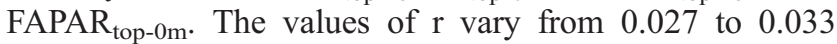
with a mean value of 0.030 , similar to the results obtained by Leitão et al. [2002], who found 0.020 for a tropical rain forest in Manaus. The $t_{\text {top- } 0 \mathrm{~m}}$ values range from 0.032 to 0.085 , with a mean value of 0.057 , and are consistent with the values obtained by Anhuf and Rollenbeck [2001], 0.045 for PAR, and by Januário et al. [1992], 0.047 for global solar radiation. FAPAR $_{\text {top- } 0 \mathrm{~m}}$ varies from 0.886 to 0.935 with a mean value of 0.914 . Figure 4 shows the monthly mean values of $\mathrm{PAR}_{\text {in }}, \mathrm{FAPAR}_{\text {top- } 0 \mathrm{~m}}$ and $\mathrm{APAR}_{\text {top-0m. }}$. FAPAR $_{\text {top- } 0 \mathrm{~m}}$ presents little variation along the year, and its lower values occur in August and September.

\subsection{Modeling}

[21] As the conversion of incident solar radiation to incident PAR may be a source of error in the estimate of modeled APAR, we include here an analysis of the simulated $\mathrm{PAR}_{\text {in }}$. Figure 5 shows the dispersion of $\mathrm{PAR}_{\text {in }}$ simulated by IBIS versus the observed values for the $\mathrm{km}$ 83 and $\mathrm{km} 67$ data, while Figure 6 shows the cumulative observed and simulated $\mathrm{PAR}_{\text {in }}$ in this ecosystem for the $\mathrm{km}$ 83 and $\mathrm{km} 67$. While the model does not tend to underestimate or overestimate the values observed for $\mathrm{km} 83$, it underestimates the $\mathrm{km} 67$ observed values by about 7\%.

[22] Figure 7a shows the simulated and observed PAR reflectance (from $\mathrm{km} 83$ ) as a function of the solar zenith angle. Although the simulated reflectance increases with the zenith angle, it underestimates the canopy PAR reflectance at very high zenith angles. The mean simulated reflectance is around 0.03 , similar to the observed. Figure $7 \mathrm{~b}$ shows the dependency of the simulated FAPAR on the solar zenith angle. FAPAR is slightly smaller when the zenith angle is greater, owing to higher reflectance (Figure 3) and higher absorptance of the sunrays by leaves and branches (longer in-canopy path). The mean simulated FAPAR value is approximately 0.76 . The direct and diffuse simulated FAPAR is shown in Figure 7c. The diffuse FAPAR remains approximately constant (0.762) for any solar angle value, while the direct FAPAR decreases with the zenith angle and its mean value is 0.769 . Figure 8 shows the monthly simulated values for PAR $_{\text {in }}$, APAR and FAPAR, showing that APAR follows $\mathrm{PAR}_{\text {in }}$ closely, and FAPAR varies slightly between 0.763 and 0.775 .

\subsection{Remote Sensing}

[23] Figure 9 shows the monthly variation of FAPAR estimated by MODIS and its QI, obtained in the $5 \times 5$ grid. During March 2002 there were no data for this grid, because of problems presented by MODIS in this period. The mean FAPAR is 0.853 throughout the period. The months with most reliable data are June and July, a period with less
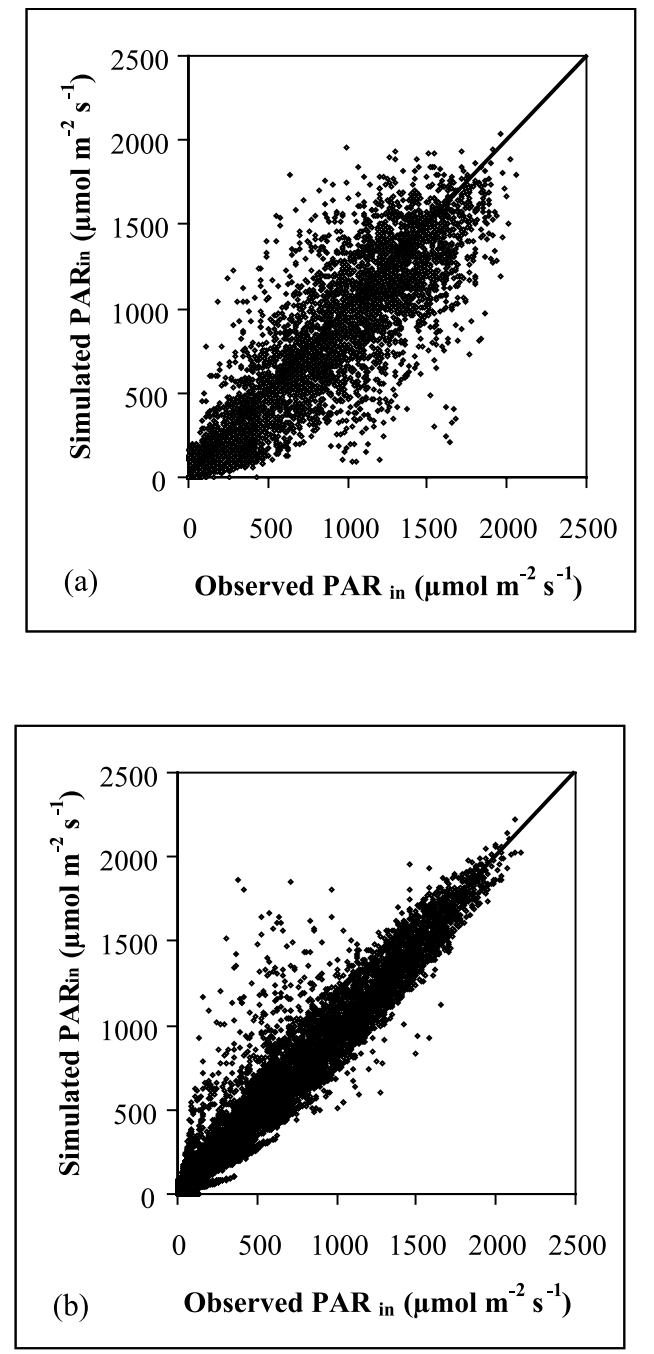

Figure 5. Simulated versus observed $\mathrm{PAR}_{\text {in }}$ for (a) $\mathrm{km} 83$ and (b) $\mathrm{km} 67$. 

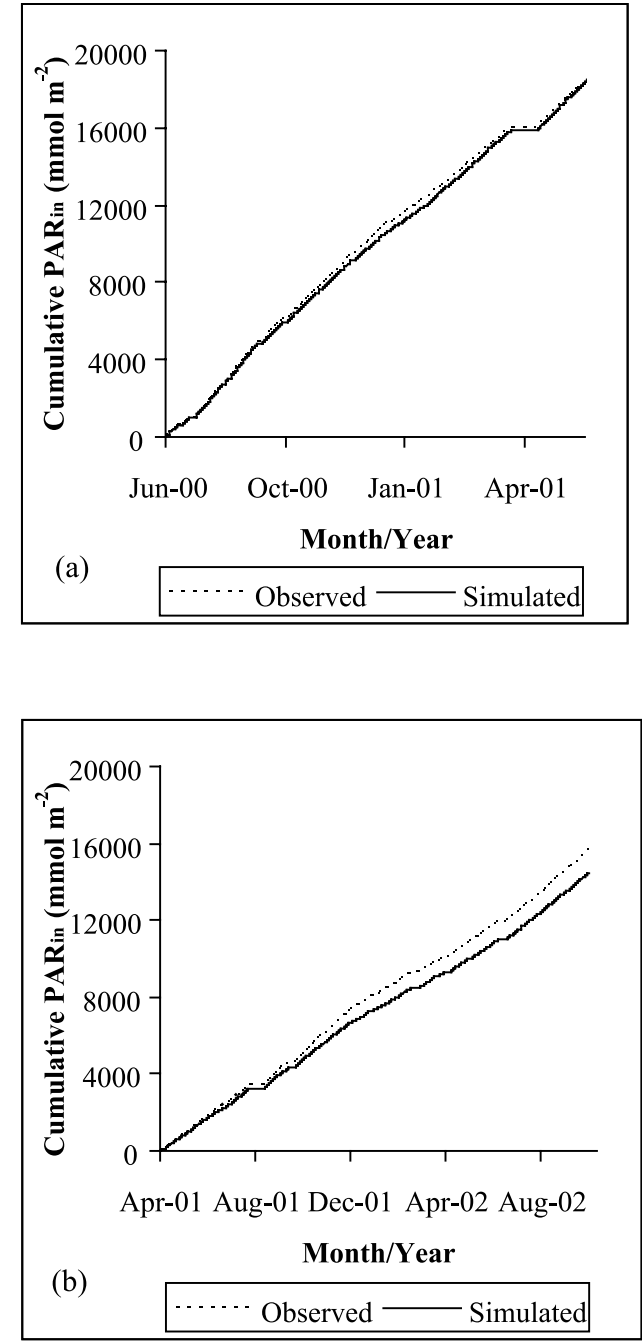

Figure 6. Cumulative $\mathrm{PAR}_{\text {in }}$ performance for all the data available for the period for the (a) $\mathrm{km} 83$ site and (b) km 67 site. Horizontal lines represent periods without observed data.

cloudiness and also high QI, i.e., periods with the high use of the main algorithm. The months with less reliable data are January, February, March and April, months with the higher rainfall rates, when the estimates are contaminated by cloudiness. The FAPAR annual means, considering the estimates by the main algorithm only and by the secondary algorithm only, are 0.815 and 0.876 , respectively, which are significantly different $\left(\mathrm{t}_{0.95,75}=1.99, \mathrm{t}_{\text {calculated }}=2.87\right)$.

[24] Most of the time, the FAPAR estimates on the Amazon were obtained via the less reliable secondary algorithm, because the constant cloudiness present in the region contaminates the measurements made by the remote sensor [Tian et al., 2004]. Thus the quality of data on the Amazon improved in the dry season, especially in July 2002.

\section{Discussion}

[25] Figure 10a shows the monthly mean FAPAR measured in the field, simulated by IBIS (averaged from daily values) and estimated by MODIS, whereas Figure $10 \mathrm{~b}$ presents monthly mean values of FAPAR at 10:30 a.m., local time. The highest values are those obtained by field measurements, followed by the MODIS estimates. The values simulated by IBIS are lower than the other estimates.

[26] Table 2 summarizes the annual mean FAPAR values of this study, and also the values by Tian et al. [2004], who
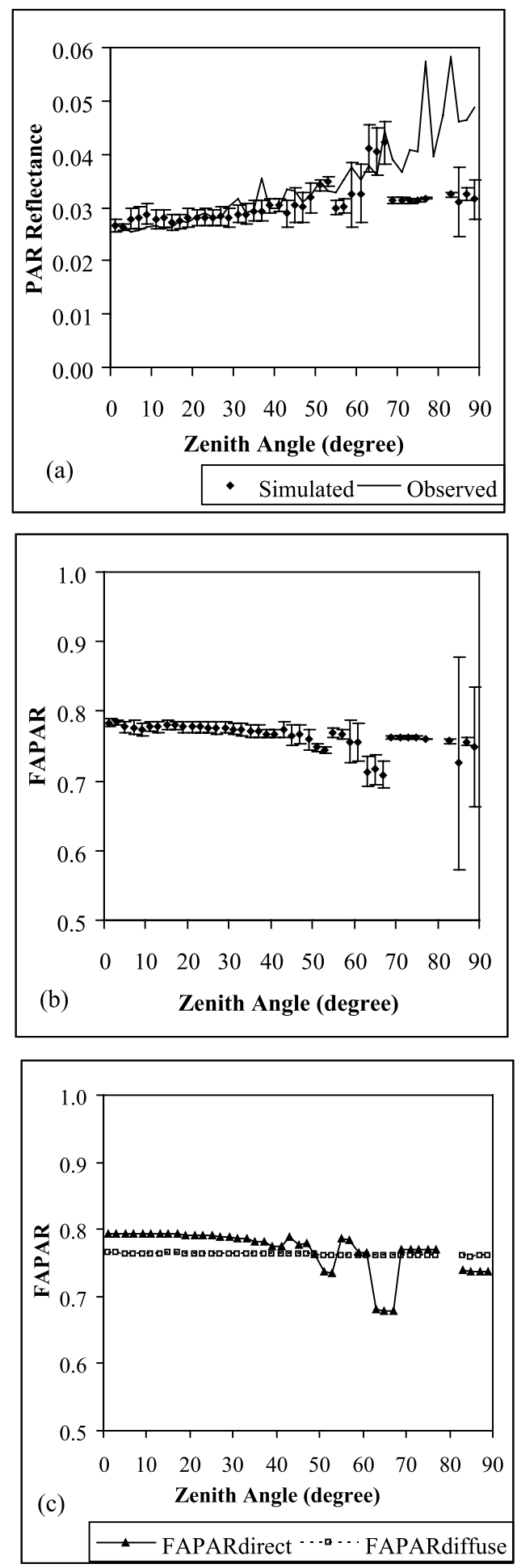

Figure 7. (a) Simulated and observed PAR reflectance, (b) simulated FAPAR, (c) simulated direct and diffuse FAPAR, as a function of the solar zenith angle. 


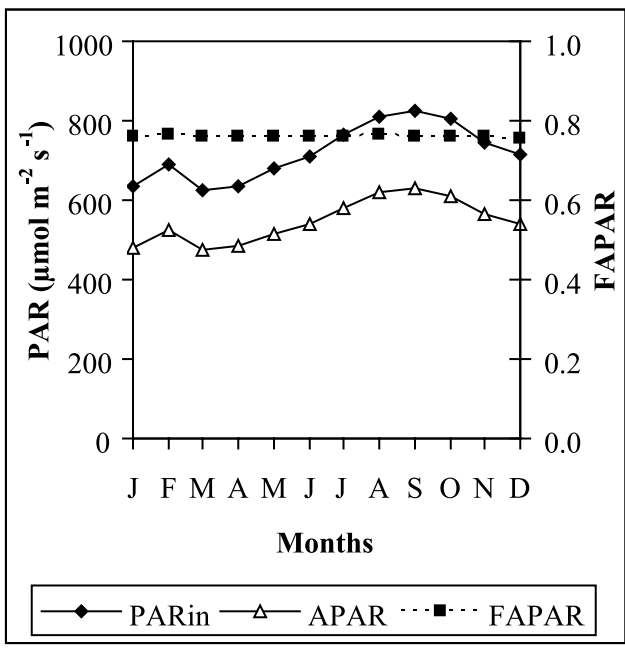

Figure 8. Monthly mean of simulated $\mathrm{PAR}_{\mathrm{in}}, \mathrm{APAR}$, and FAPAR.

compared the FAPAR obtained by CLM and MODIS for 2001 over various regions, including the Amazon. The FAPAR values found at 10:30 a.m. are slightly higher than those for the entire day. The MODIS estimated FAPAR is the same in both studies, although the model estimates by both studies are lower than the remote sensing estimates.

[27] We consider that the field measurements are the least-biased of the three estimates, despite the correction we made from $15 \mathrm{~m}$ to the ground, and the clearing of the canopy around the tower, which increases $t_{\text {top- } 15 \mathrm{~m}}$ and therefore reduces FAPAR. In the absence of a micrometeorological tower, the actual FAPAR of a tropical rain forest is probably a little higher than 0.91 .

[28] We also should consider the differences in absorption. While the MODIS algorithm determines FAPAR from the absorption of radiation by leaves only, the field observations and the IBIS simulations include PAR absorbed by leaves (proportional to the leaf area index, LAI) and by branches (proportional to the stem area index, SAI). For

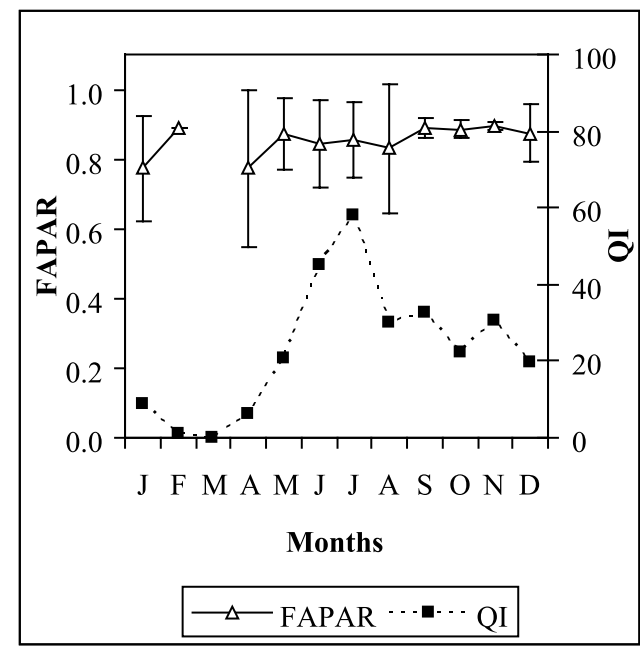

Figure 9. Monthly FAPAR mean estimated by MODIS and its quality index (QI). The bars represent the standard deviation of the spatial data.

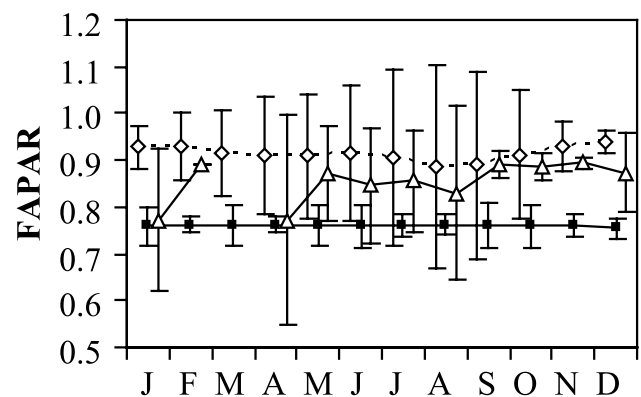

(a)

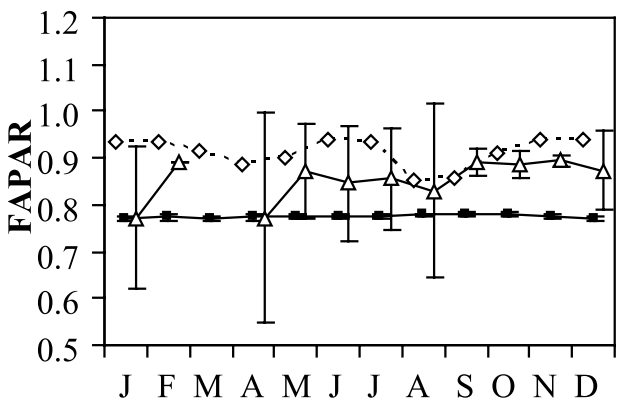

(b)

\section{Months}

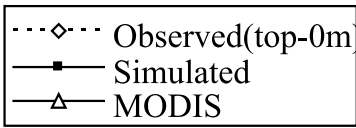

Figure 10. Monthly mean of the observed and simulated FAPAR by IBIS and estimated FAPAR by MODIS (a) throughout the day and (b) at 10:30 a.m. local time. The bars represent the standard deviation. Markers are slightly shifted horizontally to avoid overlapping of the bars.

example, if we correct the field measurements by a factor of $0.951\left(\mathrm{e}^{-0.5(\mathrm{LAI}+\mathrm{SAI})} / \mathrm{e}^{-0.5 \mathrm{LAI}}\right.$, assuming LAI $=5.6$ and $\mathrm{SAI}=0.1)$, FAPAR by leaves would be 0.87 , closer to the MODIS estimates. We should not ignore, however, that MODIS estimates are affected by atmospheric conditions, such as aerosols and cloud presence, which are very common in this region.

[29] IBIS estimates of FAPAR are somewhat low, and adjustments on the algorithm used to calculate the absorbed radiation by the canopy are necessary. As far as we could

Table 2. Comparison of the Mean Annual FAPAR Values Found in This Study For the Whole Day and at 10:30 a.m. Local Time With Those Reported by Tian et al. [2004]

\begin{tabular}{cccc}
\hline & \multicolumn{3}{c}{ FAPAR } \\
\cline { 2 - 4 } & Entire Day & \multicolumn{2}{c}{ At 10:30 a.m. } \\
\cline { 2 - 4 } & $\begin{array}{c}\text { This study, } \\
\text { Flona Tapajós } \\
\left(3^{\circ} \mathrm{S}, 55^{\circ} \mathrm{W}\right)\end{array}$ & $\begin{array}{c}\text { This study, } \\
\text { Flona Tapajós } \\
\left(3^{\circ} \mathrm{S}, 55^{\circ} \mathrm{W}\right)\end{array}$ & $\begin{array}{c}\text { Tian et al. }[2004] \\
\text { Amazon }\left(10^{\circ} \mathrm{S}-\right.\end{array}$ \\
& 0.91 & 0.93 & $\ldots$ \\
\hline $\begin{array}{c}\text { Field } \\
\text { Measurements } \\
\text { Modeling } \\
\text { MODIS }\end{array}$ & 0.76 (IBIS) & 0.77 (IBIS) & 0.83 (CLM) \\
\hline
\end{tabular}




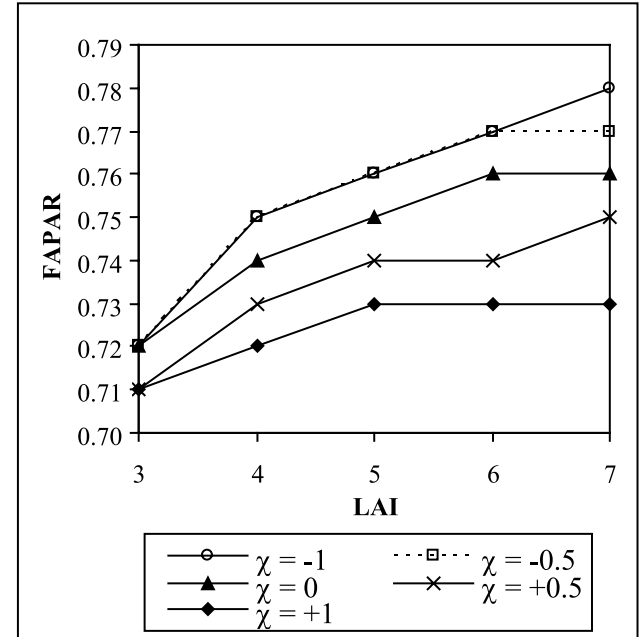

Figure 11. Sensitivity of FAPAR to LAI and leaves orientation $(\chi=-1,1$ and 0 indicate upright, horizontal, and random leaves, respectively).

investigate in several sensitivity experiments, for the range of LAI used (5 to 6), IBIS FAPAR simulations are not much sensitive to changes in canopy optical parameters (Figure 11). Although the incoming PAR and the reflection of PAR by the canopy are apparently correct, the simulations of ground radiation and soil heat flux (not shown) indicate that there is too much radiation reaching the ground as compared to actual amounts. We suggest here that the low radiation absorption by the canopy may be a consequence of simplifications introduced to the canopy radiation transfer algorithm of Sellers [1985], used by IBIS and many other models.

\section{Summary and Conclusions}

[30] This paper compares three estimates of FAPAR by an Amazonian tropical rain forest. In the Tapajós National Forest, near Santarém, state of Pará, Brazil, FAPAR is estimated based on field measurements, modeling and remotely sensed MODIS monthly FAPAR product, which has not been validated for a tropical rain forest yet. FAPAR based on field observations is calculated from incoming and reflected PAR measurements taken above the canopy, and downward PAR at a $15 \mathrm{~m}$ height, corrected to be representative of the entire canopy, obtaining an annual mean value of 0.91 . FAPAR simulated by IBIS is 0.76 , while the annual average FAPAR estimated by MODIS is 0.85 .

[31] Concluding, IBIS estimates of FAPAR are low, and an algorithm revision is necessary, while the MODIS estimates, that consider only PAR absorbed by leaves, are very close to field measurements corrected to include only the absorption by leaves. According to our results, the MODIS FAPAR product for the tropical rain forests is reliable to be used in future studies. Despite this, the proportion of missing data through the year is substantial, and the MODIS team should seriously consider improvements in both primary and secondary algorithms to increase FAPAR data existence.
[32] Acknowledgments. We thank Scott Saleska (Harvard University), Scott Miller (University of California, Irvine), and Humberto Rocha (University of São Paulo) for the field data used in this paper. Mônica Senna was supported by the Brazilian agency CNPq.

\section{References}

Anhuf, D., and R. Rollenbeck (2001), Canopy structure of the Rio Surumoni rain forest (Venezuela) and its influence on microclimate, Ecotropica, 7 , $21-32$.

Cohen, W. B., and C. O. Justice (1999), Validating MODIS terrestrial ecology products: Linking in situ and satellite measurements, Remote Sens. Environ., 70, 1-3.

Foley, J. A., I. C. Prentice, N. Ramankutty, S. Levis, D. Pollard, S. Sitch, and A. Haxeltine (1996), An integrated biosphere model of land surface processes, terrestrial carbon balance, and vegetation dynamics, Global Biogeochem. Cycles, 10, 603-628.

Friend, A. D. (1998), Parameterisation of a global daily weather generator for terrestrial ecosystem modeling, Ecol. Modell., 109(2), 121-140.

Gower, S. T., C. J. Kucharik, and J. M. Norman (1999), Direct and indirect estimation of leaf area index, FAPAR, and net primary production of terrestrial ecosystems, Remote Sens. Environ., 70, 29-51.

Januário, M., Y. Viswanadham, and R. C. Senna (1992), Radiação solar total dentro e fora de floresta tropical úmida de terra firme (Tucuruí, Pará), Acta Amazon., 22(3), 335-340.

Knyazikhin, Y., et al. (1999), MODIS leaf area index (LAI) and fraction of photosynthetically active radiation absorbed by vegetation (FPAR) product (MOD15) algorithm, theor. basis doc., NASA Goddard Space Flight Cent., Greenbelt, Md. (Available at http://modis.gsfc.nasa.gov/data/atbd/ atbd mod15.pdf)

Leitão, M. M. V. B. R., J. M. Santos, and G. M. Oliveira (2002), Estimativas do albedo em três ecossistemas da floresta amazônica, Rev. Bras. Eng. Agric. Ambient., 6, 256-261.

Mariscal, M. J., F. Orgaz, and F. J. Villalobos (2000), Modelling and measurement of radiation interception by olive canopies, Agric. For. Meteorol., 100, 183-197.

Myneni, R. B., and D. L. Williams (1994), On the relationship between FAPAR and NDVI, Remote Sens. Environ., 49, 200-211.

Myneni, R. B., et al. (2002), Global products of vegetation leaf area and fraction absorbed PAR from year one of MODIS data, Remote Sens. Environ., 83, 214-231.

Nikolov, N. T., and K. F. Zeller (1992), A solar radiation algorithm for ecosystem dynamic models, Ecol. Modell., 61, 149-168.

Nouvellon, Y., A. Bégué, M. S. Moran, D. L. Seen, S. Rambal, D. Luquet, G. Chehbouni, and Y. Inoue (2000), PAR extinction in shortgrass ecosystems: Effects of clumping, sky conditions and soil albedo, Agric. For. Meteorol., 105, 21-41.

Privette, J. L., R. B. Myneni, Y. Knyazikhin, M. Mukelabai, G. Roberts, Y. Tian, Y. Wang, and S. G. Leblanc (2002), Early spatial and temporal validation of MODIS LAI product in the Southern Africa Kalahari, Remote Sens. Environ., 83, 232-243.

Running, S. W., et al. (1994), Terrestrial remote sensing science and algorithms planned for EOS/MODIS, Int. J. Remote Sens., 15, 35873620.

Running, S. W., D. D. Baldocchi, D. P. Turner, S. T. Gower, P. S. Bakwin, and K. A. Hibbard (1999), A global terrestrial monitoring network integrating tower fluxes, flask sampling, ecosystem modeling and EOS satellite data, Remote Sens. Environ., 70, 108-127.

Saleska, S. R., et al. (2003), Carbon in Amazon forests: Unexpected seasonal fluxes and disturbance-induced losses, Science, 302, 1554-1557.

Sellers, P. J. (1985), Canopy reflectance, photosynthesis, and transpiration, Int. J. Remote Sens., 6, 1335-1372.

Tian, Y., et al. (2004), Comparison of seasonal and spatial variations of LAI/FPAR from MODIS and common land model, J. Geophys. Res., 109, D01103, doi:10.1029/2003JD003777.

Williams, M., Y. Malhi, A. D. Nobre, E. B. Rastetter, J. Grace, and M. G. P. Pereira (1998), Seasonal variation in net carbon exchange and evapotranspiration in a Brazilian rain forest: A modeling analysis, Plant Cell Environ., 21, 953-968.

M. H. Costa and M. C. A. Senna, Department of Agricultural and Environmental Engineering, Federal University of Viçosa (UFV), Av. P. H. Rolfs, s/n, CEP 36570-000, Viçosa, MG, Brazil. (mhcosta@ufv.br)

Y. E. Shimabukuro, Department of Remote Sensing, National Institute for Space Research (INPE), Av. dos Astronautas, 1758, CEP 12227-010, São José dos Campos, SP, Brazil. 